\title{
WILEY-VCH
}

DOI: 10.1002/ ((please add manuscript number))

Article type: Full Paper

\section{Effective work function reduction of practical electrodes using an organometallic dimer}

Kouki Akaike, Marco V. Nardi, Martin Oehzelt, Johannes Frisch, Andreas Opitz, Christos Christodoulou, Giovanni Ligorio, Paul Beyer, Melanie Timpel, Igor Pis, Federica Bondino, Kartikkay Moudgil, Stephen Barlow, Seth R. Marder, Norbert Koch*

Dr. K. Akaike, Dr. M. V. Nardi, Dr. M. Oehzelt, Dr. J. Frisch, Dr. A. Opitz, C. Christodoulou, G. Ligorio, P. Beyer, Dr. M. Timpel, Prof. N. Koch

Institut für Physik, Humboldt-Universität zu Berlin, Brook-Taylor-Str. 6, D-12489 Berlin, Germany

E-mail: norbert.koch@physik.hu-berlin.de

Dr. M. Oehzelt, Prof. N. Koch

Helmholtz-Zentrum Berlin für Materialien und Energie GmbH, Albert-Einstein-Str. 15, D12489 Berlin, Germany

Dr. I. Pis, Dr. F. Bondino

Elettra - Sincrotrone Trieste S.C.p.A., S.S. 14 Km 163.5, I-34149 Basovizza (TS), Italy

K. Moudgil, Dr. S. Barlow, Prof. S. R. Marder

Center for Organic Photonics and Electronics (COPE), School of Chemistry and Biochemistry, Georgia Institute of Technology, GA 30332-0400 Atlanta, USA

Keywords: organometallic dimer, work function, low-work function electrodes, air-stability, photoemission spectroscopy

* norbert.koch@physik.hu-berlin.de

\section{Abstract}

The control of the cathode work function (WF) is essential to enable efficient electron injection and extraction at organic semiconductor/cathode interfaces in organic electronic devices. The adsorption of an air-stable molecular donor onto electrodes, compatible with both evaporation and solution processes, is a simple way to reduce the WF. Such a versatile molecule, however, has not been identified yet. In this paper, ultraviolet photoelectron spectroscopy is used to confirm that depositing an ultrathin layer of the moderately air-stable pentamethylrhodocene-dimer onto various conducting electrodes, by either vacuum 


\section{WILEY-VCH}

deposition or drop-casting from solution, substantially reduces their WF to less than $3.6 \mathrm{eV}$, with $2.8 \mathrm{eV}$ being the lowest attainable value. Detailed measurements of the $\mathrm{Rh}$ core levels with X-ray photoelectron spectroscopy reveal that the electron transfer from the molecule to the respective substrates is responsible for the appreciable WF reduction. Notably, even after air-exposure, the WF of the donor-covered electrodes remains below those of typically used clean cathode-metals such as $\mathrm{Al}$ and $\mathrm{Ag}$, rendering the approach appealing for practical applications. The WF reduction, together with the observed air-stability of the covered electrodes, demonstrates the applicability of the pentamethylrhodocene-dimer to reduce the WF for a wide range of electrodes used in all-organic or organic-inorganic hybrid devices.

\section{Introduction}

An electrode with a low work function (WF) is required to promote electron injection into, or electron collection from the lowest unoccupied molecular orbital (LUMO) level of a given electron transport layer in electronic devices, such as organic light emitting diodes, field effect transistors, and photovoltaic cells. ${ }^{[1]-[2]}$ A well-known design rule to make a cathode interface ohmic is to manipulate its WF to be lower than the electron affinity of an electron transport material. ${ }^{[3]}$ When this condition holds, upon contact the Fermi level of the cathode is pinned to the LUMO of the interfacing organic semiconductor. As a result, a minimum electron injection barrier is obtained, and the molecules in proximity of the interface are ' $n$ doped' through an interfacial electron transfer from the electrodes to the molecule. ${ }^{[4]-[6]}$ In addition, the ensuing negative charges in the organic layer lead to an upward band bending. ${ }^{[4]}$ The benefits of Fermi level pinning at electrode interfaces for device performance that have been demonstrated include an increase in carrier injection efficiency, ${ }^{[7]}$ as well as less sshaped behavior in current density-voltage characteristics of organic photovoltaic cells. ${ }^{[8]}$ 


\section{WILEY-VCH}

One of the simplest ways to lower the electrode WF is the thermal deposition of an ultrathin metal layer of groups 1 or 2 , such as calcium, onto an electrode. ${ }^{[9]}$ Unfortunately, this method is not universally applicable for diverse conductors, as, for instance, alkali or alkaliearth metal ions act as charge scatterers that significantly reduce the mobility of, e.g., graphene. ${ }^{[10]}$ Moreover, these metals are sensitive to oxygen and moisture in air, which is detrimental to the performance and lifetime of organic devices. ${ }^{[9]}$ Organic electron-donors, on the other hand, can form large and stable ions, which decrease their ability to act as electrostatic charge traps. ${ }^{[11]}$ Some organic donors, such as $1,1^{\prime}$-dimethyl- $1 H, 1^{\prime} H$ [4,4']bipyridinylidene $[\mathrm{MV}(0)]$ and 2-(2-methoxyphenyl)-1,3-dimethyl-2,3-dihydro- $1 H$ benzoimidazole (MeO-DMBI), and 1,1,2,2-tetrakis(dimethylamino)ethene (TDAE) have been found to reduce the WF of metal substrates through electron transfer from these dopants to the substrate. ${ }^{[12]-[15]}$ However, these reported materials appear to be not versatile from the application point of view, because of the instability of the neutral state in air ${ }^{[16]}$ and the restriction to only some electrode materials to completely cause electron transfer. ${ }^{[14]}$ Therefore, finding a molecular donor, compatible with both vacuum-deposition and solution processes such as drop-casting, is desirable to be incorporated as a WF-reducer for bottom and top electrodes into all-solution processed or multilayer devices. ${ }^{[17]-[18]}$

The dimers formed by some 19-electron organometallic sandwich compounds, such as the dimer of 1,2,3,4,5-pentamethylrhodocene (1, molecular structure shown in Figure 1), are promising candidates for this purpose: their reductant ability has already been demonstrated by the effective $n$-doping for a variety of organic semiconductors, ${ }^{[19]}$ their 18 -electron configurations lead to moderate air-stability, and they can be processed using both vacuum deposition at low temperature $\left(\sim 120^{\circ} \mathrm{C}\right)$ and solution processes. ${ }^{[19]}$ Indeed, the Ir analogue of $\mathbf{1}_{\mathbf{2}}$ has been used to reduce the WF of ITO, $\mathrm{ZnO}$, and $\mathrm{Au}$ via dip-coating, ${ }^{[20]}$ and the dimer of ruthenium pentamethylcyclopentadienyl mesitylene has been shown to reduce the WF of ITO by dip-coating ${ }^{[20]}$ and that of $\mathrm{ZnO}$ through vacuum processing, ${ }^{[21]}$ and $\mathbf{1}_{\mathbf{2}}$ has been used to 


\section{WILEY-VCH}

reduce the WF of CVD graphene by dip-coating. ${ }^{[11]}$ However, the general applicability of this approach to other device-relevant electrode materials has not been investigated. Moreover, none of these previous studies has directly compared the effectiveness of vacuum and solution processing, nor has the air-stability of dimer-modified electrodes, which is required for airprocessed devices, been investigated in detail.

In this report, we demonstrate the usability of $\mathbf{1}_{\mathbf{2}}$ for reducing the WF of a wide range of practical electrode materials, including air-exposed gold and silver (air-Au and air-Ag), $\mathrm{UV} / \mathrm{O}_{3}$ treated- and poly(ethylenedioxythiophene):poly(styrenesulfonate) (PEDOT:PSS)coated indium tin oxide (ITO), as well as molybdenum oxide $\left(\mathrm{MoO}_{\mathrm{x}}\right)$, employing ultraviolet and X-ray photoelectron spectroscopy (UPS and XPS, respectively). Upon vacuum-depositing $\mathbf{1}_{2}$, the WFs for most of the electrodes substantially decrease to ca. $2.9 \mathrm{eV}$. Even for $\mathrm{MoO}_{\mathrm{x}}$, which has the highest WF among the substrates selected in this study, the WF decreases to that of clean magnesium. We also found that drop-casting $\mathbf{1}_{2}$ reduced the WF of $\mathrm{UV} / \mathrm{O}_{3}-\mathrm{ITO}$ and PEDOT:PSS such that the modified material is applicable as low-WF electrodes in electronic devices. The analysis of the XPS spectra revealed that the appreciable WF reduction is attributed to the electron transfer from the adsorbed donor to the respective substrates. Moreover, it is found that the low WF character remains even after air-exposure. Notably, modified electrodes prepared by drop-casting were found to be even more air-stable than their vacuum-deposited counterparts. The present results demonstrate the general capability of $\mathbf{1}_{\mathbf{2}}$ to reduce the WFs of a wide range of device-relevant electrodes.

\section{Results \& Discussion}

\subsection{Work function reduction by evaporation}

Figure 2(a) shows the WF changes upon evaporating $\mathbf{1}_{\mathbf{2}}$ for the various electrode materials measured with UPS. For (i) air-Ag, (ii) air-Au, and (iii) PEDOT:PSS, depositing the ultrathin 


\section{WILEY-VCH}

$\mathbf{1}_{2}$ layer $(<2 \mathrm{~nm})$ substantially reduced their WF to $2.8-3.0 \mathrm{eV}$, which is in agreement with the WF obtained when $n$-doping CVD graphene with $\mathbf{1}_{2}$ by dip-coating. ${ }^{[1]}$ The large WF reduction was also observed for clean $\mathrm{Au}(111)$, where the $\mathrm{WF}$ reached $2.7 \mathrm{eV}$ following the deposition of $15 \AA \mathbf{1}_{\mathbf{2}}$ [Figure S1(a)]. The similarly low WF of air-Au suggests that surface contamination of the gold substrate does not significantly influence the magnitude of the WF reduction using $\mathbf{1}_{2}$. In the valence region [Figure 2(b)], changes from the spectral signature of each substrate can be observed: features attributable to the electronic states of the adsorbate are clearly visible at high coverage. We found that the spectral shape featuring the bands $\mathrm{A}-\mathrm{C}$ resembles the valence spectrum of a cobaltocene multilayer adsorbed on a cooled graphite substrate, ${ }^{[22]}$ therefore, bands A-C are assigned to neutral $\mathbf{1}_{\mathbf{2}}$, with band A corresponding to photoelectron emission from its highest occupied molecular orbital (HOMO) level.

It is noted that the valence spectrum at the highest coverage for (iv) $\mathrm{UV} / \mathrm{O}_{3}-\mathrm{ITO}$ is not identical to that for the above-mentioned substrates, although the WF of the $\mathrm{UV} / \mathrm{O}_{3}-\mathrm{ITO}$ is reduced to $2.8 \mathrm{eV}$ as well. The subtracted spectrum at $9.5 \AA$ in (iv) of Figure 2(b) shows that the bands D-F with an energy separation different from that of the bands A-C contribute to the valence spectrum [(iv) of Figure 2(b)]. These features could result from the presence of oxidized $\mathbf{1}_{2}$ (i.e. the cationic monomer, $\mathbf{1}^{+}$), because the same was measured also in the spectra at $1.5 \AA$ and $2.2 \AA$ on PEDOT:PSS (the intensity of peak D is too weak to be detected), where most of $\mathbf{1}_{\mathbf{2}}$ in contact with PEDOT:PSS is likely converted into $\mathbf{1}^{+}$through oxidation by $\mathrm{PEDOT}^{+}{ }^{[23]}$ The results of the $\mathrm{Rh} 3 \mathrm{~d}$ core-level measurements presented later on [Figure 3(a)] support the assignment of the bands A-F.

Using the onset of the $\mathbf{1}_{\mathbf{2}}$ HOMO-derived peak [band A in Figure 2(b)] and corresponding WF, the ionization energy (IE) of neutral $\mathbf{1}_{2}$ for air-Ag, air-Au and PEDOT:PSS substrates was determined to be $(3.5 \pm 0.2) \mathrm{eV}$. The obtained value is in reasonable agreement with the IE estimated by cyclic voltammetry. ${ }^{[1]}$ Since the IE of $\mathbf{1}_{\mathbf{2}}$ is lower than the WF of all used substrates in this study [Figure 2(a)], HOMO level pinning occurs, where electrons are 


\section{WILEY-VCH}

transferred from the molecules to the substrates in order to achieve electronic equilibrium. ${ }^{\text {[24]- }}$ ${ }^{[25]}$ As a result, the ensuing WF upon evaporation of $\mathbf{1}_{\mathbf{2}}$ onto the substrates commonly decreased to 2.8-3.0 eV [see Figure 2(a)]. In the present case, the interfacial electron transfer converts the neutral $\mathbf{1}_{\mathbf{2}}$ to the cationic monomers of $\mathbf{1}_{\mathbf{2}}\left(\mathbf{1}^{+}\right) .{ }^{[1],[19], \text { [20] }}$ The positive potential caused by the resulting surface layer of $\mathbf{1}^{+}$cations leads to the WF reduction of the substrates.

The substantial WF reduction for the above-mentioned substrates prompted us to evaporate $\mathbf{1}_{2}$ onto a high-WF substrate, (v) $\mathrm{MoO}_{\mathrm{x}}$. Despite the non-negligible quantity of oxygen defects, which is confirmed by the band located at a binding energy of ca. $1 \mathrm{eV}$ in the valence spectrum [indicated by an arrow in (v) of Figure $2(b)],{ }^{[26]}$ the WF of the prepared $\mathrm{MoO}_{\mathrm{x}}$ was $6.6 \mathrm{eV},{ }^{[27]}$ which is significantly higher than those of all other substrates [Figure 2(a)]. The vacuum deposition of $\mathbf{1}_{\mathbf{2}}$ onto the $\mathrm{MoO}_{\mathrm{x}}$ results in the reduction of WF to $3.7 \mathrm{eV}$. Interestingly, further prolonged evaporation did not significantly affect the secondary electron cutoff (SECO) and valence spectra [the top spectra in (v) of Figures 2 (a) and (b)].

We suggest that the limited WF reduction for $\mathrm{MoO}_{\mathrm{x}}$ can be explained as follows. A huge fraction of the $\mathbf{1}_{\mathbf{2}}$-layer even at multilayer coverages has to be immediately converted to $\mathbf{1}^{+}$, because an appreciable charge transfer is required to achieve electronic equilibrium between the high-WF $\mathrm{MoO}_{\mathrm{x}}$ substrate and the strong reductant $\mathbf{1}_{2}$. The $\mathrm{WF}$ of the $\mathrm{MoO}_{\mathrm{x}}$ is actually 3.7 $\mathrm{eV}$ at nominal thickness of $5.6 \AA$, which is still higher than the ionization energy of $\mathbf{1}_{\mathbf{2}}(3.5$ $\mathrm{eV}$ ) and in principle allows further electron transfer to $\mathrm{MoO}_{\mathrm{x}}$. As a result, it is difficult for $\mathbf{1}_{2}$ to remain neutral on the $\mathrm{MoO}_{\mathrm{x}}$ surface. In this scenario, the repulsive Coulomb interaction between neighboring $\mathbf{1}^{+}$might overcome the energetic stabilization by the electron transfer and thermodynamically destabilizes the interface, which would consequently suppress further adsorption of the molecule. This presumably accounts for less WF-reduction [(v) of Figure 2(a)] compared to the other substrates and for minor spectral changes for $\mathrm{MoO}_{\mathrm{x}}$ even after prolonged evaporation. Actually, the photoemission from oxygen-defect states is never completely attenuated [see (v) of Figure 2(b)]. 


\section{WILEY-VCH}

The analysis of the XPS spectra revealed that the electrons are transferred from the adsorbed $\mathbf{1}_{\mathbf{2}}$ to the substrate. Figure $3(\mathrm{a})$ shows the thickness-dependent $\mathrm{Rh} 3 \mathrm{~d}$ core level spectra for the $\mathbf{1}_{\mathbf{2}}$-covered substrates. Due to spin-orbit coupling, a doublet is expected; this is fitted by two Voigt functions with an energy separation of $4.74 \mathrm{eV}$. For air-Ag, air-Au, PEDOT:PSS and UV/O ${ }_{3}$-ITO, the component at around $309.3 \mathrm{eV}$, which is assigned to $\mathrm{Rh}^{\mathrm{I}}$ (corresponding to the unreacted $\mathbf{1}_{2}$, red-colored), ${ }^{[11]}$ is gradually enhanced with increasing thickness, while the component at around $310.6 \mathrm{eV}$, attributed to $\mathrm{Rh}^{\mathrm{III}}$ (blue-colored, corresponding to formation of cationic monomer $\left.\mathbf{1}^{+}\right),{ }^{[1]}$ is predominant at low coverages. These observations verify the electron transfer from $\mathbf{1}_{\mathbf{2}}$ to the substrates, through the Fermi level pinning to the HOMO of $\mathbf{1}_{\mathbf{2}}$. We note that the differences in binding energy (with respect to the Fermi level) of $\mathrm{Rh} 3 \mathrm{~d}$ peaks at each thickness are mostly due the difference in the sample WF values.

For the $\mathrm{MoO}_{\mathrm{x}}$ case [(v) in Figure 3(a)], two Voigt functions were required to obtain adequate fitting results. In addition to the $\mathbf{1}^{+}$component $(310.8 \mathrm{eV}$, blue-colored), a feature around $309.8 \mathrm{eV}$ was found for a film thickness of $5.6 \AA$ (green-colored). In contrast to the $\mathbf{1}_{\mathbf{2}}$ component observed for the other substrates, the fraction of the low-BE component monotonically decreased upon evaporating 12. This means that the new feature is not resulting from neutral $\mathbf{1}_{2}$ but $\mathbf{1}^{+}$. The energy shift towards lower BE by $1 \mathrm{eV}$ with respect to the "normal" $\mathbf{1}^{+}$component is most likely attributable to the screening by the negative electrostatic potential originated from non-bonding electrons at oxygen defects present on the $\mathrm{MoO}_{\mathrm{x}}$ surface [see (v) of Figure 2(b)]

The variation of the $\mathrm{Rh} 3 \mathrm{~d}$ spectra could also explain the difference in the UPS spectra at the highest coverages [see Figure 2(b)]. The area ratios of $\mathbf{1}_{2^{-}}$to $\mathbf{1}^{+}$-derived peaks were 3.42 , 1.48, and 1.44 for air-Ag, air-Au, and PEDOT:PSS respectively. The same estimation was carried out for $\mathrm{UV} / \mathrm{O}_{3}-\mathrm{ITO}$, where a value of 0.69 was found. Consequently, for this small ratio, the quantity of $\mathbf{1}^{+}$on the UV/O $/$-ITO is larger than that for the other substrates. With 


\section{WILEY-VCH}

this in mind, we could rationalize the assignment of the valence spectra. That is, the bands DF observed in the valence spectra for the ITO substrate [(iv) of Figure 2(b)] can be attributed to the molecular levels of $\mathbf{1}^{+}$cations, while the bands A-C are assigned to the levels of neutral $1 \mathbf{1}$

According to a recent theoretical study on the electronic structure of $\mathbf{1}_{\mathbf{2}},{ }^{[28]}$ the HOMO of 12, to which band A can be assigned, mainly consists of the rhodium $d$-orbital, some cyclopentadienyl $\pi$-contributions, and a $\mathrm{C}-\mathrm{C} \sigma$-bonding contribution associated with the central bond of the molecule, whereas the HOMO-1, to which $\mathrm{B}$ can be assigned, is similar to the HOMO, but lacking the $\sigma$-bonding contributions. Band $\mathrm{C}$ is attributed to ionization from several molecular orbitals that can have substantial rhodium $d$-orbital contributions with varying additional cyclopentadienyl $\pi$-orbital contributions. ${ }^{[28]}$

The evolution of the $C 1 \mathrm{~s}$ core level spectra corresponds well with that of the $R \mathrm{~h} 3 \mathrm{~d}$ spectra [Figure 3(b)]. The two components, assigned to carbons of cyclopentadienyl ligands in $\mathbf{1}^{+}$and $\mathbf{1}_{\mathbf{2}}$ (blue- and red-colored components, respectively), were found with the same peak area ratios as those for $\mathrm{Rh} 3 \mathrm{~d}$ spectra. Again for $\mathrm{MoO}_{\mathrm{x}}$, a fraction of $\mathbf{1}^{+}$is destabilized by the electrons at oxygen defects and the energetic splitting between the two components is reduced [green-colored, (v) of Figure 3(b)].

In contrast, for PEDOT:PSS, the evolution of the $\mathrm{C}$ 1s spectra shows a unique nominal thickness dependence when evaporating $\mathbf{1}_{2}$. The spectrum of neat PEDOT:PSS could be fitted with two components located at $284.1 \mathrm{eV}$ and $285.6 \mathrm{eV}$ [yellow-colored, (iii) of Figure 3(b)]. The former is assignable to saturated and conjugated carbons, and the latter to the C-O-C units in PEDOT. ${ }^{[29]}$ At nominal thicknesses of $1.5 \AA$ and $2.2 \AA$, a new component emerges at $285.0 \mathrm{eV}$ [purple-colored, (iii) of Figure 3(b)], as well as a $\mathbf{1}^{+}$-derived component located at $285.7 \mathrm{eV}$ (blue-colored). Because only pure $\mathbf{1}^{+}$exists for low coverages, as seen in the $\mathrm{Rh} 3 \mathrm{~d}$ core level spectra [(iii) of Figure 3(a)], the new component can be associated with the carbons 


\section{WILEY-VCH}

in PEDOT:PSS, most likely, surface-segregated PSS ${ }^{-}{ }^{[30]}$ Its origin might be the stabilization of $\mathrm{PSS}^{-}$by the positive potential of the adsorbed $\mathbf{1}^{+}$. At the highest coverage [the top spectrum in (iii) of Figure 3(b)], both $\mathbf{1}^{+}$and $\mathbf{1}_{2}$-derived components, together with an attenuated PEDOT:PSS signal, contribute to the whole spectrum.

The changes in the core levels for most of the substrates were essentially negligible (Figure S2), despite the noticeable interface electron transfer. Once again, the core levels of PEDOT:PSS showed unique evolutions upon deposition of $\mathbf{1}_{\mathbf{2}}$. A new component emerges in the O 1s spectrum at a thickness of $2.2 \AA$ on the PEDOT:PSS substrate [blue-colored, (ii) of Figure S2(c)], which suggests that portions of cationic PEDOT chains in the polymer matrix may be reduced to neutral portions by the electrons supplied from the adsorbed $\mathbf{1}_{2}$. Similar interface reactions were inferred from vacuum-level shifts at the pentacene/PEDOT:PSS interface. $^{[23]}$

The Mo 3d spectra for the $\mathrm{MoO}_{\mathrm{x}}$ substrate showed a gradual evolution upon evaporating 12: The fraction of $\mathrm{Mo}^{\mathrm{V}}$ increases from initially $40 \%$ to $50 \%$ [Figure 4(a)]. This strongly indicates that a fraction of $\mathrm{Mo}^{\mathrm{VI}}$ is electron-doped by $\mathbf{1}_{\mathbf{2}}$. Concurrently, the Mo $3 \mathrm{~d}$ peak shifts towards higher $\mathrm{BE}$ by $0.5 \mathrm{eV}$. The origin for this energy level shift in the $\mathrm{MoO}_{\mathrm{x}}$ layer is the generation of a (in first approximation linear) potential gradient across $\mathrm{MoO}_{\mathrm{x}},{ }^{[32]}$ as a result of the HOMO level pinning of $\mathbf{1}_{2} \cdot{ }^{[24]-[25]}$ The electrostatic field gradually shifts the conduction band (CB) of the $\mathrm{MoO}_{\mathrm{x}}$ layer to a point, where it reaches the Fermi level [Figure 4(b)]. Simultaneously, to achieve electronic equilibrium through the heterostructure, electrons from the gold substrate (onto which $\mathrm{MoO}_{\mathrm{x}}$ was deposited) fill the $\mathrm{CB}$ consisting of Mo $4 \mathrm{~d}$ orbitals ${ }^{[26]-[27]}$ and consequently convert $\mathrm{Mo}^{\mathrm{VI}}$ into $\mathrm{Mo}^{\mathrm{V}}$ [Figure 4(a)].

In Figure 5, the resulting WF after the evaporation of $\mathbf{1}_{\mathbf{2}}$ is shown as a function of initial substrate WF $\left(\mathrm{WF}_{\text {sub }}\right)$ and indicated by red closed circles. The final WF for the used electrodes, except for $\mathrm{MoO}_{\mathrm{x}}$, are commonly reduced to $2.9 \mathrm{eV}$ (red solid line in Figure 5). ${ }^{[33]}$ The independence of the resulting WFs from $\mathrm{WF}_{\text {sub }}$ strongly suggests HOMO level pinning. It 


\section{WILEY-VCH}

should also be noted that the obtained WF is sufficiently lower than electron affinities of most electron transport materials $(3-5 \mathrm{eV}) \cdot{ }^{[35]-[36]}$ Consequently, this energetic scenario will lead to LUMO level pinning with typical electron transport materials ${ }^{[4]-[6]}$ and a minimum electron injection barrier can be assured for their contacts. One might speculate that $\mathbf{1}^{+}$and/or $\mathbf{1}_{\mathbf{2}}$ diffuse into an organic film deposited on the modified substrate, as demonstrated for a $p$ dopant. ${ }^{[37]}$ Since $\mathbf{1}^{+}$is electrostatically bound to the substrate surface owing to the interfacial electron transfer to the substrate, the diffusion of $\mathbf{1}^{+}$should be unfavorable. On the other hand, neutral $\mathbf{1}_{\mathbf{2}}$ may diffuse into organic film, and electron-dope it, which would even improve, e.g., carrier transport. $^{[38]}$

\subsection{Work function reduction by drop-casting}

To further examine the usability of $\mathbf{1}_{2}$ in reducing WF, we drop-cast $\mathbf{1}_{\mathbf{2}}$ onto $\mathrm{UV} / \mathrm{O}_{3}$ ITO and PEDOT:PSS. The measurements of the SECO spectra revealed that even a simple drop-casting of $\mathbf{1}_{2}$, followed by rinsing with toluene to remove weakly adsorbed molecules, effectively reduces the WFs to $3.3 \mathrm{eV}$ for $\mathrm{UV} / \mathrm{O}_{3}-\mathrm{ITO}$ and $3.6 \mathrm{eV}$ for PEDOT:PSS [Figure 6(a)]. Note that the final WF is ca. $0.5 \mathrm{eV}$ higher than those obtained by vacuum-deposition (see Figure 5). In contrast to the valence band spectra for $\mathbf{1}_{2}$-sublimed UV/O 3 -ITO and PEDOT:PSS [(iii) and (iv) of Figure 2(b)], the spectral features for the drop-cast samples are less pronounced [red curve in Figure 6(b)]. This may imply that the number of the molecules in the drop-cast layer is insufficient to give distinct photoemission signals similarly to the vacuum-deposition cases. Nevertheless, the obtained WF values are comparable to those of polyethylenimine ethoxylated (PEIE)-coated substrates. ${ }^{[16]}$ The $\mathrm{Rh} 3 \mathrm{~d}$ core level spectra indicate the presence of $\mathbf{1}^{+}$[Figure 6(c)], suggesting that the mechanism of the WF reduction again involves an electron transfer from $\mathbf{1}_{\mathbf{2}}$ to the respective substrate. The finding that dropcasting of $\mathbf{1}_{\mathbf{2}}$ can be used to alter archetypical electrodes (even covered with a high-WF 


\section{WILEY-VCH}

polymer layer) to low-WF cathodes will enable $\mathbf{1}_{\mathbf{2}}$ to be incorporated as an interlayer in a device structure by solution processing techniques, including printing.

\subsection{Impact of air-exposure on $1_{2}$-covered electrodes}

Finally, we investigated the air-stability of the $\mathbf{1}_{\mathbf{2}}$-covered electrodes with UPS and XPS, in order to evaluate the applicability of $\mathbf{1}_{\mathbf{2}}$ even to all-air-processed devices. ${ }^{[39]}$ Figure 7(a) displays the WF shifts for the $\mathbf{1}_{\mathbf{2}}$-evaporated substrates after air-exposure for $4 \mathrm{~min}$. The apparent increase of the WF can be seen for all substrates, but, importantly, the low WF character remains $(\mathrm{WF}<3.9 \mathrm{eV}$ ). The $\mathrm{Rh} 3 \mathrm{~d}$ peaks shift towards lower BE (Figure 8) upon the air-exposure, fully in line with the WF increases.

The WF increase can be attributed to the reduction of $\mathrm{H}_{2} \mathrm{O} / \mathrm{O}_{2}$ by (excess) neutral $\mathbf{1}_{2}$ and/or by the electrons transferred initially to substrate. ${ }^{[20]}$ As a result, possible reaction products from the ambient gases, most likely $\mathrm{OH}^{-}$and $\mathrm{O}_{2}^{-}$, may be generated and weaken the initial interface dipoles with the negative charges at the substrate side. The enhanced $\mathrm{O} 1 \mathrm{~s}$ peak after the air-exposure supports this mechanism (Figure S3).

The air-exposure concurrently alters the valence band spectra for all substrates, except for the $\mathrm{UV} / \mathrm{O}_{3}-\mathrm{ITO}$. The changes are seen by the transformation of the spectral signature for neutral $\mathbf{1}_{2}$ bands A-C towards that for $\mathbf{1}^{+}$bands D-F [Figure 7(b)], indicating that the short air-exposure oxidizes remaining $\mathbf{1}_{\mathbf{2}}$ and generates additional cationic monomers. Consistent with this, the $\mathrm{Rh}^{\mathrm{III}}$ component (blue-colored) becomes prominent for all substrates, as measured in the Rh $3 \mathrm{~d}$ core level spectra (Figure 8). Note that the increase of the $\mathrm{Rh}^{\mathrm{III}}$ fraction is almost negligible for $\mathrm{UV} / \mathrm{O}_{3}$-ITO [(iv) of Figure 8]. Since most of the adsorbates on this substrate are already oxidized by the interface charge transfer before air-exposure [(iv) of Figure 2], additional oxidation through air-exposure cannot induce significant further changes.

In Figure 5, the resulting WF values after air-exposure $\left(\mathrm{WF}_{\mathrm{air}}\right.$, open red circles) are also plotted as a function of substrate $\mathrm{WF}\left(\mathrm{WF}_{\text {sub }}\right)$. Noteworthy, now the amplitude of the WF 


\section{WILEY-VCH}

increase appears to be linearly correlated with $\mathrm{WF}_{\text {sub }}$, i.e., $\mathrm{WF}_{\text {air }}=\mathrm{WF}_{\text {sub }}-1.3 \mathrm{eV}$ (red dashed line). Before air-exposure, higher-WF substrates (like PEDOT:PSS) are essentially more electron-doped by adsorption of $\mathbf{1}_{\mathbf{2}}$, because more electron transfer is required to achieve electronic equilibrium. Since the magnitude of the reduction of the ambient molecules at the substrate interface may depend on the quantity of the electrons initially transferred to substrate side, $\mathrm{WF}_{\text {air }}$ shows a linear relation with $\mathrm{WF}_{\text {sub }}$. Such an interface degradation by airexposure may reduce Coulomb attraction force that stick $\mathbf{1}^{+}$to the substrates. As a result, a fraction of $\mathbf{1}^{+}$(likely bound to the aerial anions to balance charge) can desorb from the substrates, which is evidenced by the attenuated area-intensity of $\mathrm{Rh} 3 \mathrm{~d}$ peaks by over $8 \%$ after air-exposure (Figure 8), due to its small molecular weight during evacuating load-lock chamber before measurements for air-exposed $\mathbf{1}_{2}$-evaporated substrates. Correspondingly, the core-level intensity of the substrate is increased after air-exposure (except $\mathrm{UV} / \mathrm{O}_{3}-\mathrm{ITO}$, see Figure S4), which again accounts for the molecular desorption.

Interestingly, the impact of air-exposure on $\mathbf{1}_{2}$ drop-cast onto PEDOT:PSS and $\mathrm{UV} / \mathrm{O}_{3}$ ITO was found to be less when compared to the vacuum-deposition counterparts. Their WF values remain unchanged even after air-exposure for $5 \mathrm{~min}$. [Figure 9(a)], although a slight increase of $\mathbf{1}^{+}$can be seen in the Rh $3 d$ core level spectra [Figure 9(b)]. A prolonged airexposure for $24 \mathrm{~h}$ increases the WF of $\mathbf{1}_{2}$-covered $\mathrm{UV} / \mathrm{O}_{3}$-ITO to $3.6 \mathrm{eV}$. Notably, the final WF is still $0.8 \mathrm{eV}$ lower than that of the untreated $\mathrm{UV} / \mathrm{O}_{3}-\mathrm{ITO}$. From a practical point of view, these results indicate that solution-processed $\mathbf{1}_{2}$ layers are advantageous for obtaining a sufficiently low-WF electrode with higher long-term stability.

The minor impact of air-exposure on the drop-cast modified electrodes may be explained as follows: $\mathrm{H}_{2} \mathrm{O}, \mathrm{O}_{2}$, and/or other impurities remaining in the $\mathbf{1}_{\mathbf{2}}$-solution can react with either $\mathbf{1}_{\mathbf{2}}$ or with electrons transferred from $\mathbf{1}_{\mathbf{2}}$ to the substrate, so that there are already species such as $\mathbf{1}^{+} \mathrm{OH}^{-}$present on the substrate in addition to $\mathbf{1}_{\mathbf{2}}$ and $\mathbf{1}^{+}$prior to air exposure. Indeed, the WF of the as-cast substrates [Figure 5, blue closed squares] were already as high as $\mathrm{WF}_{\text {air }}$ for 


\section{WILEY-VCH}

$\mathbf{1}_{2}$-evaporated substrates [Figure 5, red open circles]. Therefore, the degradation in air for the drop-cast substrates is less significant than that for their vacuum-deposited counterparts, which are free of air-contamination due to the processing conditions.

\section{Conclusions}

We have shown that the pentamethylrhodocene-dimer, $\mathbf{1}_{2}$, can reduce the WF of all tested electrode materials by both vacuum-deposition and drop-casting. As summarized in Figure 5, upon vacuum-deposition of $\mathbf{1}_{\mathbf{2}}$-ultrathin layer $(1-2 \mathrm{~nm})$, the electrode WF decreases to $2.9 \mathrm{eV}$. A simple drop-casting of $\mathbf{1}_{\mathbf{2}}$ from toluene solution also results in the WF reduction to $3.3 \mathrm{eV}$ and $3.6 \mathrm{eV}$ for the $\mathrm{UV} / \mathrm{O}_{3}-\mathrm{ITO}$ and PEDOT:PSS, respectively. A detailed analysis of XPS spectra revealed that the electron transfer from $\mathbf{1}_{2}$ to the substrates generates the cationic monomer $\mathbf{1}^{+}$right at the interface to the substrate. The resulting positive potential at the interface leads to the appreciable WF reduction. These results also help rationalize the injection barrier reduction upon contact doping of $\mathrm{Au}$ electrodes with rhodocene dimers and the resulting improved electron mobility of $\mathrm{C}_{60}$ field-effect transistors. ${ }^{[38]}$ We also confirmed that the low-WF character remains even after air exposure, which is consistent with the previous results. ${ }^{[20]}$ The resulting WF for the air-exposed (up to $24 \mathrm{~h}$ ) electrodes is still lower than $4 \mathrm{eV}$, which is comparable to prototypical cathode buffer-layers such as titanium dioxide that are frequently used in OPV cells. ${ }^{[39]}$ Notably, the drop-cast modified electrodes were found to be more air-stable than their vacuum-deposited counterparts. The versatility of the pentamethylrhodocene dimer to produce low-WF electrodes of practical relevance demonstrated in the present study, confirms that dimeric organometallics can reduce the WF of stable electrodes (e.g. Au), which should be beneficial in a wide range of applications such as all-organic or organic-inorganic hybrid devices.

\section{Experimental Section}




\section{WILEY-VCH}

\subsection{Materials}

The molecule $\mathbf{1} \mathbf{2}$ was synthesized as previously described in refs. 40 and 41 . It was sealed in a glass bottle and was stored in a glove box filled with $\mathrm{N}_{2}\left(\mathrm{O}_{2}, \mathrm{H}_{2} \mathrm{O}<0.1 \mathrm{ppm}\right)$ until further use. $\operatorname{Ag}(111)$ and $\operatorname{Au}(111)$ substrates were prepared by repeated Ar-ion sputtering and annealing $\left(500^{\circ} \mathrm{C}\right)$ cycles. Air-Ag and air-Au were obtained by exposing the cleaned $\mathrm{Ag}(111)$ and $\mathrm{Au}(111)$ to ambient air for $1 \mathrm{~h}$. ITO substrates were ultrasonicated in acetone and isopropanol for $10 \mathrm{~min}$. each, followed by UV-ozone treatment for $15 \mathrm{~min}$. The bare ITO substrates treated by this procedure are referred as $\mathrm{UV} / \mathrm{O}_{3}-\mathrm{ITO}$ throughout this manuscript. The PEDOT:PSS (Clevios P VP AI 4083) substrate was prepared on the $\mathrm{UV} / \mathrm{O}_{3}$-ITO by spincoat at $3000 \mathrm{rpm}$ for $30 \mathrm{~s}$ and annealed at $120^{\circ} \mathrm{C}$ for $20 \mathrm{~min}$ in air to dry the film. To prepare a high-WF substrate, $2 \mathrm{~nm} \mathrm{MoO}_{\mathrm{x}}$ (Sigma-Aldrich) was in situ vacuum-deposited on the cleaned $\mathrm{Au}(111) . \mathbf{1}_{2}$ was vacuum-deposited onto the prepared substrates in a preparation chamber.

For the UPS/XPS measurements on solution-processed substrates, $\mathbf{1}_{\mathbf{2}}$ was dissolved in toluene at concentration of $2.5 \mathrm{mM}$ and drop-casted on UV/O $\mathrm{O}_{3}-\mathrm{ITO}$ and PEDOT:PSS in a $\mathrm{N}_{2-}$ filled glove box. These drop-casted substrates were left there for $10 \mathrm{~min}$ to ensure the molecular adsorption on their surfaces, followed by rinsing them with toluene to remove weakly adsorbed molecules. The drop-casted samples were transferred from the glove box to the UPS/XPS chamber under low vacuum.

After completing the measurements for the $\mathbf{1}_{\mathbf{2}}$-precovered substrates, samples were exposed to ambient air in a load-lock chamber. The air-exposed samples were then evacuated and transferred back to the analysis chamber.

\subsection{Photoelectron spectroscopy}

The UPS and XPS measurements on the $\mathbf{1}_{2}$-precovered substrates (except for a clean $\mathrm{Au}(111)$ substrate), prepared by vacuum-deposition, were performed at the end station 


\section{WILEY-VCH}

SurICat (beamline PM4) at the synchrotron light source BESSY II (Berlin, Germany). Excitation energies of $35 \mathrm{eV}$ and $620 \mathrm{eV}$ (for $\mathrm{MoO}_{\mathrm{x}}, 46$ and $480 \mathrm{eV}$ ) were used for UPS and XPS, respectively. There, the ultrahigh vacuum system consists of interconnected sample preparation (base pressure: $1 \times 10^{-8} \mathrm{mbar}$ ) and analysis (base pressure: $1 \times 10^{-10} \mathrm{mbar}$ ) chambers. The spectra were collected with a hemispherical electron energy analyzer (Scienta SES 100) set to an energy resolution of $120 \mathrm{meV}$.

UPS measurements for the clean $\mathrm{Au}(111)$ were performed at the synchrotron light source Elettra, Triest (Italy), where an excitation energy of $40 \mathrm{eV}$ was used. The ultrahigh vacuum system there consists of interconnected sample preparation (base pressure: $2 \times 10^{-9}$ mbar) and analysis (base pressure: $2 \times 10^{-10}$ mbar) chambers. The spectra were collected with a hemispherical electron-energy analyzer (Scienta R3000) set to an energy resolution of 100 meV.

The UPS and XPS spectra for the drop-cast substrates were recorded in a lab-system consisting again of an analysis chamber (base pressure: $1 \times 10^{-9}$ mbar) connected to a loadlock chamber (base pressure: $5 \times 10^{-8}$ mbar), using He I resonance line and nonmonochromated $\mathrm{Al} \mathrm{K \alpha}$ as excitation sources for UPS and XPS, respectively. An Omicron EA125 hemispherical energy analyzer was used to collect the spectra (energy resolutions for UPS and XPS measurements, determined from the Au Fermi edge and the Au $4 f_{7 / 2}$ peak, were $180 \mathrm{meV}$ and $1.25 \mathrm{eV}$, respectively). The error of XPS binding energies retrieved from curve fitting is estimated to be smaller than $50 \mathrm{meV}$, as obtained from procedures where binding energies were offset on purpose. Nominal thicknesses of $\mathbf{1}_{\mathbf{2}}$ were estimated from the attenuation of the intensities of core levels for each substrate, assuming layer-by-layer growth of $1_{2}$. The SECO spectra were measured with a sample bias of $-10 \mathrm{~V}$ to clear the analyzer WF. All measurements were performed at room temperature.

\section{Supporting Information}




\section{WILEY-VCH}

Supporting Information is available from the Wiley Online Library or from the author.

\section{Acknowledgements}

K.A. acknowledges financial support by the Alexander von Humboldt foundation. Work at Georgia Tech was supported by the 2013 Global Research Outreach (GRO) Program of the Samsung Advanced Institute of Technology (SAIT) and Samsung Research America, Silicon Valley (SRA-SV) and by the National Science Foundation (DMR-1305247). Work in Berlin was supported by the DFG (SFB951) and the Helmholtz Energy Alliance "Hybrid Photovoltaics". The research leading to these results has received funding from the European Community's Seventh Framework Programme (FP7/2007-2013) under grant agreement $n^{\circ}$ 312284 .

Received: ((will be filled in by the editorial staff))

Revised: ((will be filled in by the editorial staff)) Published online: ((will be filled in by the editorial staff))

\section{References}

[1] L.-M. Chen, Z. Xu, Z. Hong, Y. Yang, J. Mater. Chem. 2010, 20, 2575.

[2] R. Steim, F. R. Kogler, C. J. Brabec, J. Mater. Chem. 2010, 20, 2499.

[3] Y. Shen, A. R. Hosseini, M. H. Wong, G. G. Malliaras, ChemPhysChem. 2004, 5, 16.

[4] H. Wang, P. Amsalem, G. Heimel, I. Salzmann, N. Koch, M. Oehzelt, Adv. Mater. 2014, 26, 925 .

[5] J. Niederhausen, P. Amsalem, A. Wilke, R. Schlesinger, S. Winkler, A. Vollmer, J. P. Rabe, N. Koch, Phys. Rev. B 2012, 86, 081411(R).

[6] P. Amsalem, J. Niederhausen, A. Wilke, G. Heimel, R. Schlesinger, S. Winkler, A. Vollmer, J. P. Rabe, N. Koch, Phys. Rev. B 2013, 87, 035440.

[7] S.-J. Yoo, J.-H. Chang, J.-H. Lee, C.-K. Moon,C.-I. Wu, J.-J. Kim, Sci. Rep. 2014, 4, 3902.

[8] J. Wagner, M. Gruber, A. Wilke, Y. Tanaka, K. Topczak, A. Steindamm, U. Hörmann, A. Opitz, Y. Nakayama, H. Ishii, J. Pflaum, N. Koch, W. Brütting, J. Appl. Phys. 2012, 111, 054509. 


\section{WILEY-VCH}

[9] C. Y. Jiang, X. W. Sun, D. W. Zhao, A. K. K. Kyaw, Y. N. Li, Sol. Energy Mater. Sol. Cells 2010, 94, 1618.

[10] J. -H. Chen, C. Jang, S. Adam, M. S. Fuhrer, E. D. Williams, M. Ishigami, Nature Phys. 2008, 4, 377.

[11] S. A. Paniagua, J. Baltazar, H. Sojoudi, S. K. Mohapatra, S. Zhang, C. L. Henderson, Samuel Graham, S. Barlow, S. R. Marder, Mater. Horiz. 2014, 1, 111.

[12] B. Bröker, R.-P. Blum, J. Frisch, A. Vollmer, O. T. Hofmann, R. Rieger, K. Müllen, J. P. Rabe, E. Zojer, N. Koch, Appl. Phys. Lett. 2008, 93, 243303.

[13] B. Bröker, R.-P. Blum, L. Beverina, O. T. Hofmann, M. Sassi, R. Ruffo, G. A. Pagani, G. Heimel, A. Vollmer, O. J. Frisch, J. P. Rabe, E. Zojer, N. Koch, ChemPhysChem. 2009, 10, 2947.

[14] P. Wei, N. Liu, H. R. Lee, E. Adijanto, L. Ci, B. D, Naab, J. Q. Zhong, J. Park, W. Chen, Y. Cui, Z. Bao, Nano Lett. 2013, 13, 1890.

[15] W. Osikowicz, X. Crispin, C. Tengstedt, L. Lindell, T. Kugler, W. R. Salaneck, Appl. Phys. Lett. 2004, 85, 1616.

[16] Y. Zhou, C.F, Herrnandez, J. Shim, J. Meyer, A. J. Giordano, H. Li, P. Winget, T. Papadopoulos, H. Cheun, J. Kim, M. Fenoll, A. Dindar, W. Haske, E. Najafabadi, T. M. Khan, H. Sojoudi, S. Barlow, S. Graham, J.-L. Brédas, S. R. Marder, A. Kahn, B. Kippelen, Science, 2012, 336, 327 .

[17] Y.-H. Chen, L.-Y. Liu, K.-T. Wong, J. Wen, D. J. Miller, S. B. Darling, J. Am. Chem. Soc. 2012, 134, 13616.

[18] M. Liu, M. B. Johnston, H. J. Snaith, Nature, 2013, 501, 395.

[19] S. Guo, S. B. Kim, S. K. Mohapatra, Y. Qi, T. Sajoto, A. Kahn, S. R. Marder, S. Barlow, Adv. Mater. 2012, 24, 699.

[20] A. J. Giordano, F. Pulvirenti, T. M. Khan, C. Fuentes-Hernandez, K. Moudgil, J. H. Delcamp, B. Kippelen, S. Barlow, S. R. Marder, ACS Appl. Mater. Interf. 2015, 7, 4320. 


\section{WILEY-VCH}

[21] R. Schlesinger, F. Bianchi, S. Blumstengel, C. Christodoulou, R. Ovsyannikov, B.

Kobin, K. Moudgil, S. Barlow, S. Hecht, S.R. Marder, F. Henneberger, N. Koch, Nature Commun. 2015, 6, 6754.

[22] O. Henrion and W. Jaegermann, Surf. Sci. 1997, 387, L1073.

[23] N. Koch, A. Elschner, J. P. Rabe, R. L. Johnson, Adv. Mater. 2005, 17, 330.

[24] A. Wilke, P. Amsalem, J. Frisch, B. Bröker, A. Vollmer, N. Koch, Appl. Phys. Lett. 2011, 98, 123304.

[25] K. Akaike, N. Koch, M. Oehzelt, Appl. Phys. Lett. 2014, 105, 223303.

[26] M. T. Greiner, L. Chai, M. G. Helander, W.-M. Tang, Z.-H. Lu, Adv. Funct. Mater. 2013, 23, 215.

[27] K. Kanai, K. Koizumi, S. Ouchi, Y. Tsukamoto, K. Sakanoue, Y. Ouchi, K. Seki, Org. Electron. 2010, 11, 188.

[28] S. K. Mohapatra, A. Fonari, C. Risko, K. Yesudas, K. Moudgil, J. H. Delcamp, T. V. Timofeeva, J.-L. Brédas, S. R. Marder, S. Barlow, Chem. Eur. J. 2014, 20, 1.

[29] S.K.M. Jönsson, J. Birgerson, X. Crispin, G. Greczynski, W. Osikowicz, A. W. Denier van der Gon, W. R. Salaneck, M. Fahlman, Synth. Met. 2003, 139, 1.

[30] G. Greczynski, T. Kugler, M. Keil, W. Osikowicz, M. Fahlman, W. R. Salaneck, J. Electron. Spec. Relat. Phenom. 2001, 121, 1.

[31] Y. Gassenbauer and A. Klein, J. Phys. Chem. B 2006, 110, 4793.

[32] M. Oehzelt, N. Koch, G. Heimel, Nat. Commun. 2014, 5, 4174.

[33] Relatively large deviations from the averaged WF values for PEDOT:PSS and clean Au can be explained as follows: (i) For PEDOT:PSS, the original surface dipole, owing to the surface segregation of $\mathrm{PSS}^{-}$[30], may partly cancel the interface dipole formed by electron transfer from the Rh-dimer to the substrate. This can rationalize the larger WF for the modified PEDOT:PSS. (ii) For clean Au, the pushback effect, in which the spilled electron density of a metal surface is pushed back to the metal side upon molecular adsorption [34], 


\section{WILEY-VCH}

can also lead to the WF reduction in addition to the electron transfer-induced interface dipole. This effect can result in a lower work function than the averaged value.

[34] H. Ishii, K. Sugiyama, E. Ito, K. Seki, Adv. Mater. 1999, 11, 605.

[35] A. P. Kulkarni, C. J. Tonzola, A. Babel, S. A. Jenekhe, Chem. Mater. 2004, 16, 4556.

[36] Y. Lin and X. Zhan, Mater. Horiz. 2014, 1, 470.

[37] A. Dai, A. Wan, C. Magee, Y. Zhang, S. Barlow, S. R. Marder, A. Kahn, Org. Electron. 2015, 23, 151.

[38] S. Singh, S. K. Mohapatra, A. Sharma, C. F. Hernandez, S. Barlow, S. R. Marder, B. Kippelen, Appl. Phys. Lett. 2013, 102, 153303.

[39] S. Jung, A. Sou, K. Banger, D.-H. Ko, P. C. Y. Chow, C. R. McNeill, H. Sirringhaus, Adv. Energy Mater. 2014, 4, 1400432.

[39] A. Imanishi, E. Tsuji, Y. Nakato, J. Phys. Chem. C 2007, 111, 2128.

[40] S. Guo, S. K. Mohapatra, A. Romanov, T. V. Timofeeva, K. I. Hardcastle, K. Yesudas, C. Risko, J.-L. Brédas, S. R. Marder, S. Barlow, Chem. Eur. J. 2012, 18, 14760.

[41] O. V. Gusev, L. I. Denisovich, M. G. Peterleitner, A. Z. Rubezhov, N. A. Ustynyuk, P. M. Maitlis, J. Organomet. Chem. 1993, 452, 219. 


\section{WILEY-VCH}

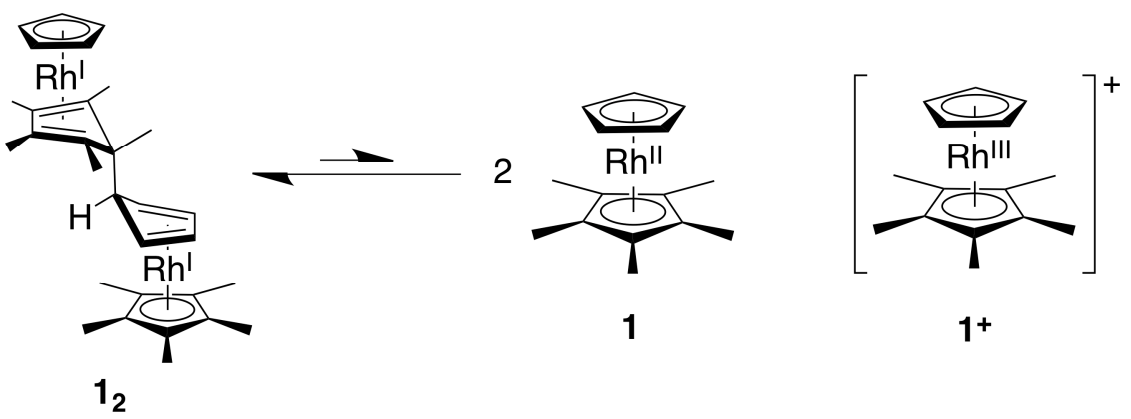

Figure 1. Molecular structures of a neutral rhodocene-dimer (1 $\left.\mathbf{1}_{\mathbf{2}}\right)$, neutral monomer (1), and cationic monomer $\left(\mathbf{1}^{+}\right)$.

(a) work function
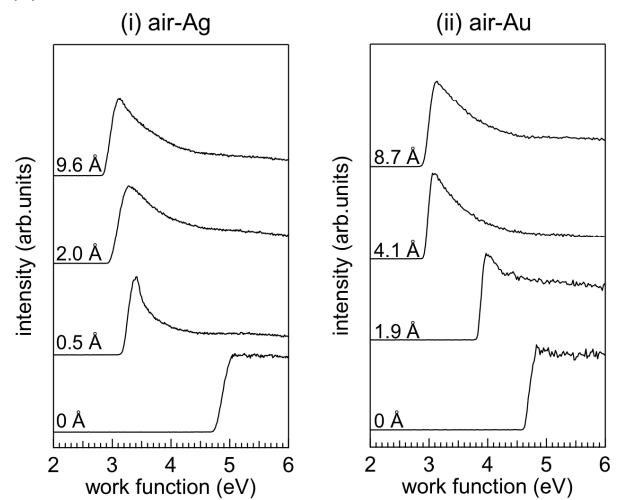

(b) valence

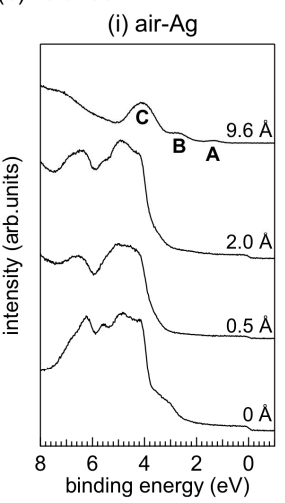

(ii) air-Au

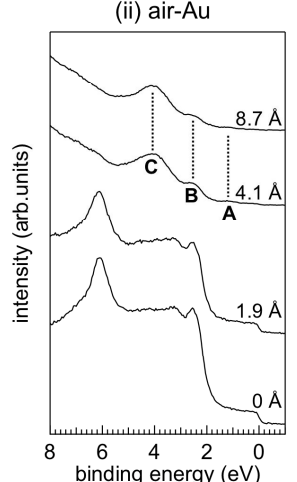

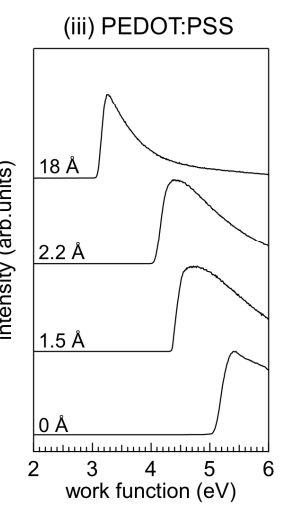
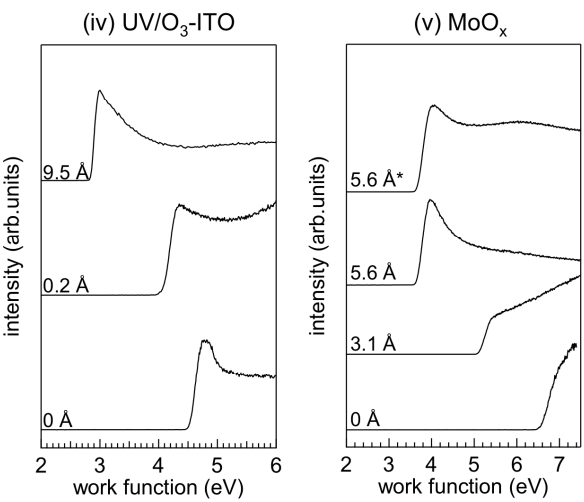

(iii) PEDOT:PSS

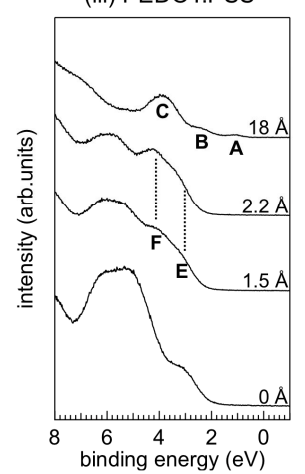

(iv) $\mathrm{UV} / \mathrm{O}_{3}-\mathrm{ITO}$

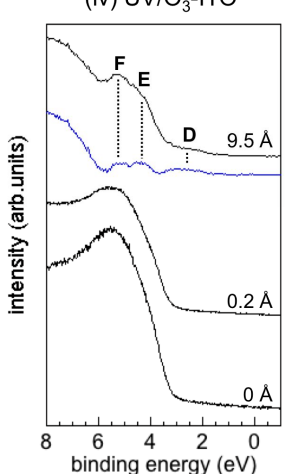

(v) $\mathrm{MoO}_{\mathrm{x}}$

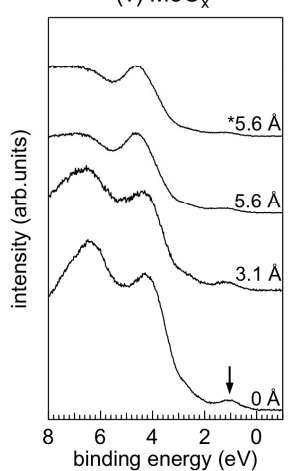

Figure 2. (a) Work function changes of electrodes upon evaporating $\mathbf{1}_{\mathbf{2}}$. (b) Corresponding valence band spectra. Bands $\mathrm{A}-\mathrm{C}$ and $\mathrm{D}-\mathrm{F}$ are assigned to photoelectron emissions from $\mathbf{1}_{2}$ and $\mathbf{1}^{+}$, respectively. In (iv) of (b), the subtracted spectrum for a $9.5 \AA$ layer is also shown in blue to separate bands D-F from the signal of the bottom ITO substrate. The arrow in (v) indicates the oxygen-defect states. The top spectra in (v), marked with an asterisk, were measured after a prolonged evaporation of $\mathbf{1}_{2}$ for $125 \mathrm{~min}$. (the nominal $5.6 \AA$ layer was obtained by intermittent evaporations for a total of $160 \mathrm{~min}$.) 
(a) Rh 3d
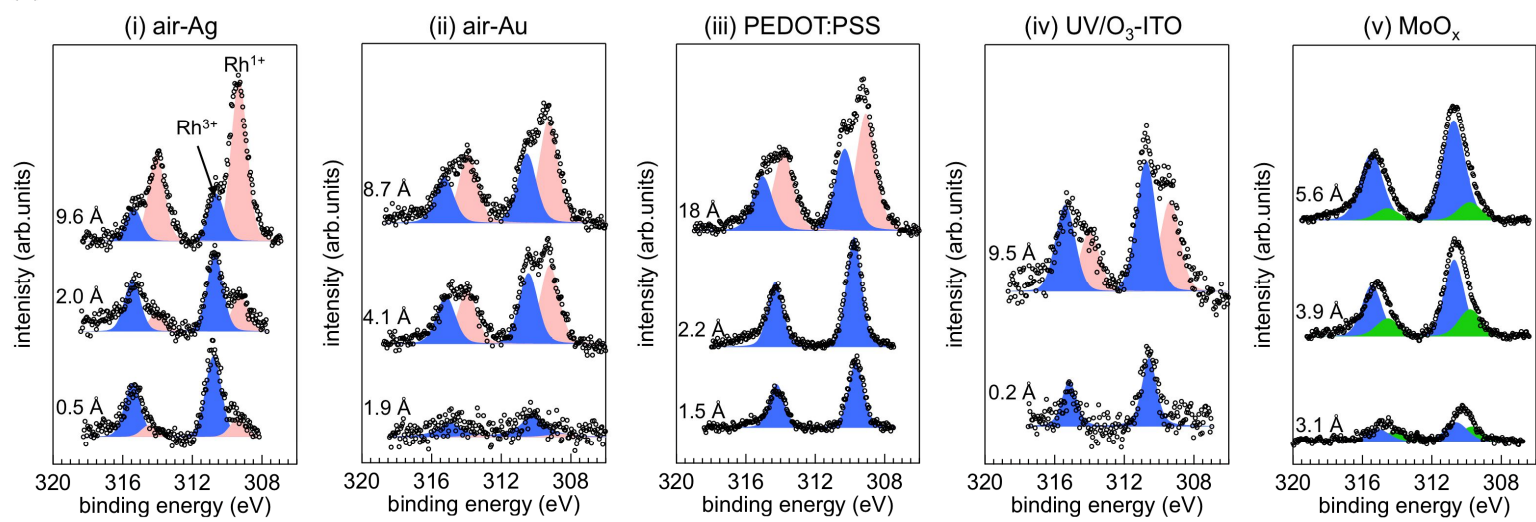

(b) C $1 \mathrm{~s}$
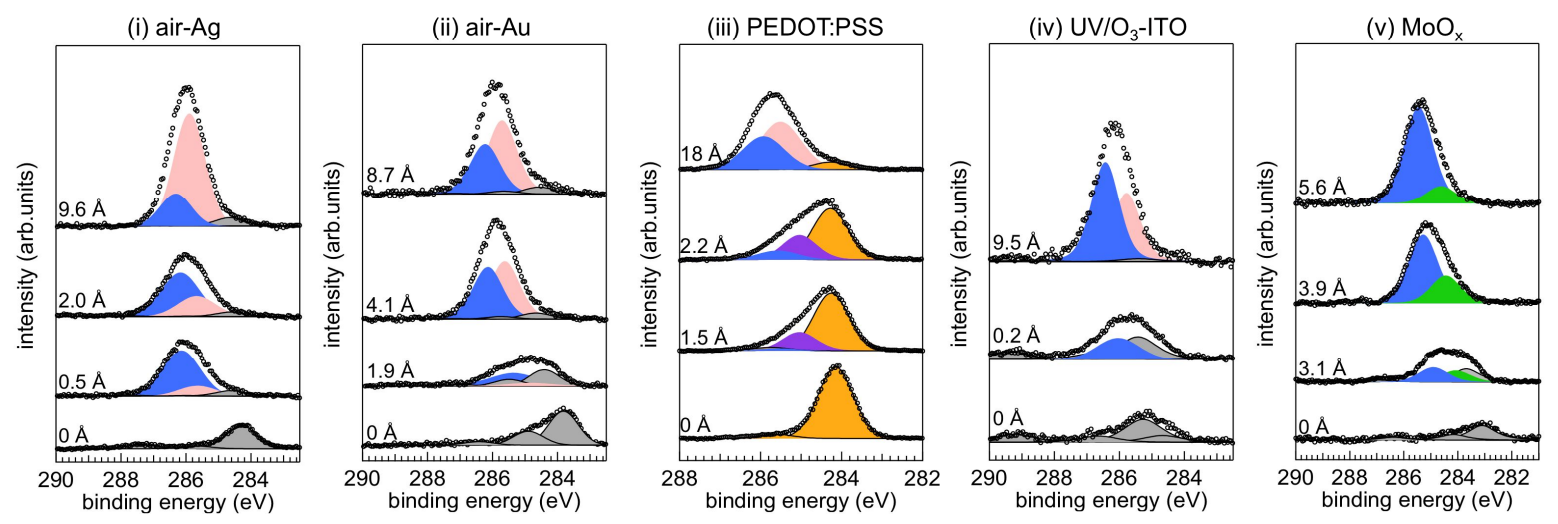

Figure 3. Evolution of XPS spectra for the $\mathbf{1}_{\mathbf{2}}$-covered electrodes in the $\mathrm{Rh} 3 \mathrm{~d}$ (a) and $\mathrm{C} 1 \mathrm{~s}(\mathrm{~b})$ regions. Gray components in (b) are from adventitious carbons. The peak located at $289.2 \mathrm{eV}$ in (v) is assigned to the carboxylic groups, generated by breaking bonds of carbon contaminants on the ITO surface. ${ }^{[31]}$ Yellow and purple components in (iii) of (b) are both assigned to carbons of PSS, the latter stabilized by adsorbed $\mathbf{1}^{+}$. 


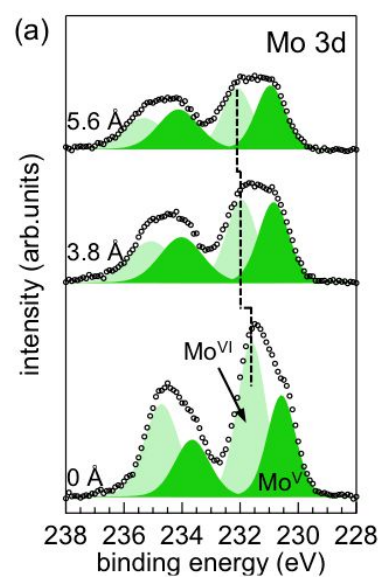

(b)

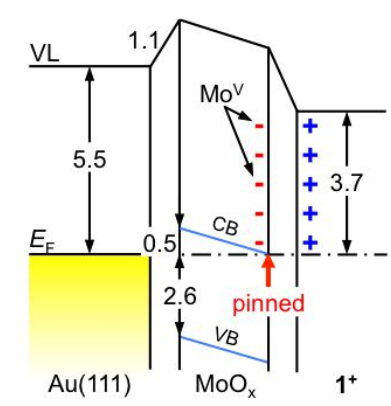

Figure 4. (a) Evolution of Mo $3 \mathrm{~d}$ core level spectra for the $\mathbf{1}_{2}$-covered $\mathrm{Au}(111) / \mathrm{MoO}_{\mathrm{x}}$ electrode. The dashed lines are guides to visualize the peak shifts. (b) Schematic energy level diagram for the $\mathrm{Au}(111) / \mathrm{MoO}_{\mathrm{x}} / \mathbf{1}_{\mathbf{2}}$ heterojunction. $\mathrm{CB}$ and $\mathrm{VB}$ denote the conduction and valence bands of $\mathrm{MoO}_{x}$, respectively. The band gap value of $\mathrm{MoO}_{\mathrm{x}}$ was taken from Ref. 27.

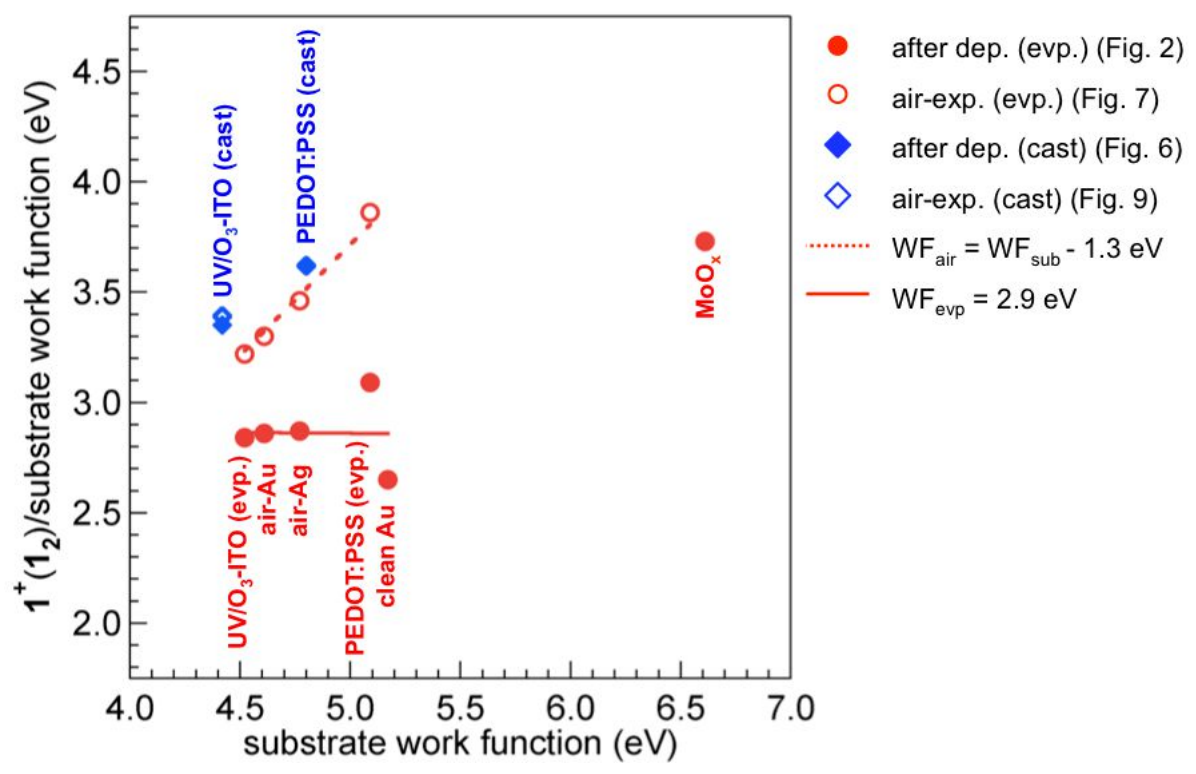

Figure 5. Work function of $\mathbf{1}_{\mathbf{2}}$-covered electrodes prepared by vacuum-deposition and dropcasting plotted as a function of initial substrate work function $\left(\mathrm{WF}_{\text {sub }}\right)$. WF values after airexposure $\left(\mathrm{WF}_{\mathrm{air}}\right)$ are also included. 


\section{WILEY-VCH}

(a) work function

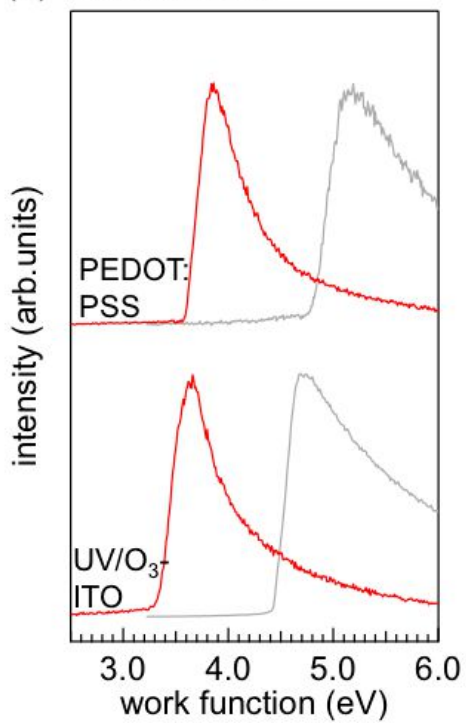

(b) valence

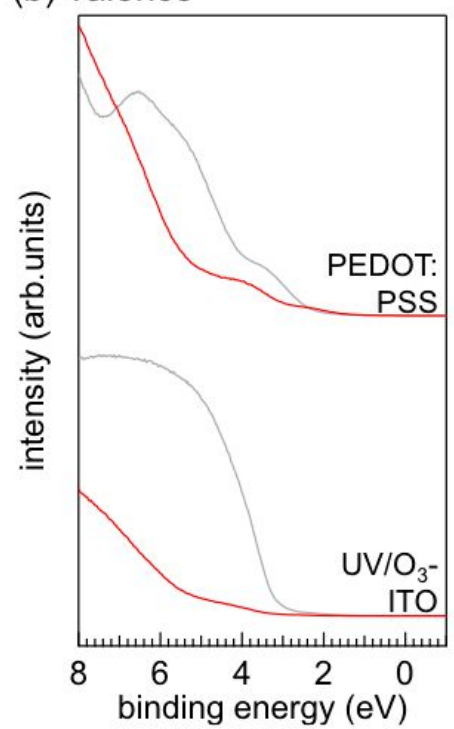

(c) Rh 3d

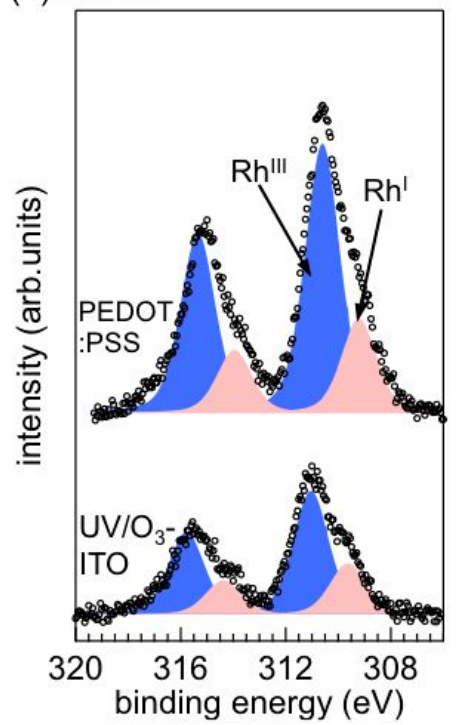

Figure 6. (a) Work function shift for $\mathrm{UV} / \mathrm{O}_{3}$-treated and PEDOT:PSS-covered ITO substrates upon drop-casting $\mathbf{1}_{\mathbf{2}}$. The $\mathbf{1}_{\mathbf{2}}$-covered substrates were rinsed by toluene to remove weakly adsorbed molecules in a $\mathrm{N}_{2}$-filled glove box. Gray and red curves are spectra before and after drop-casting $\mathbf{1}_{2}$, respectively. (b) Valence band spectra for the bare and $\mathbf{1}_{\mathbf{2}}$-covered substrates [colors correspond to (a)]. (c) Rh $3 \mathrm{~d}$ core level spectra for the $\mathbf{1}_{\mathbf{2}}$ drop-cast substrates.

(a) work function

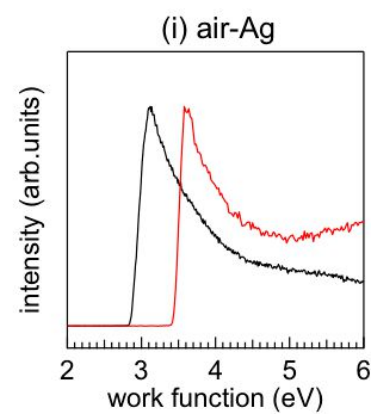

(b) valence

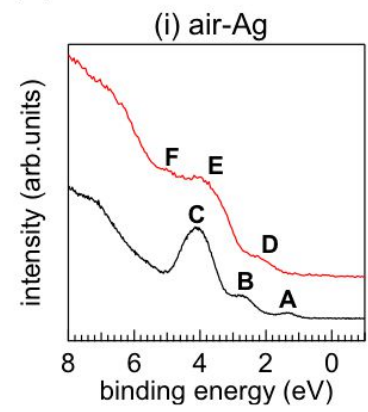

(ii) air-Au

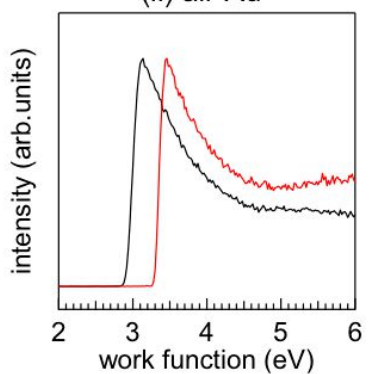

(ii) air-Au

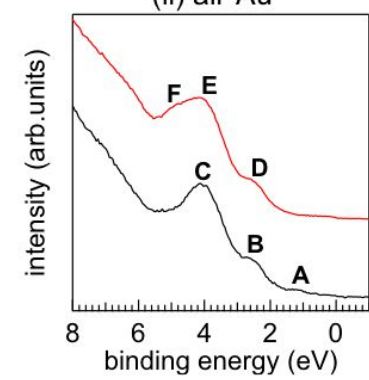

(iii) PEDOT:PSS

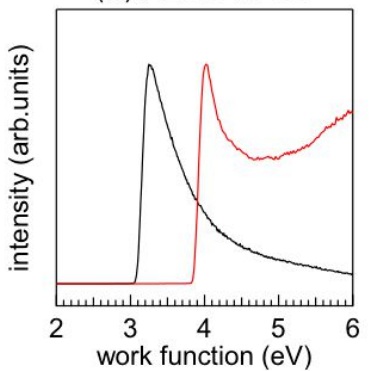

(iii) PEDOT:PSS

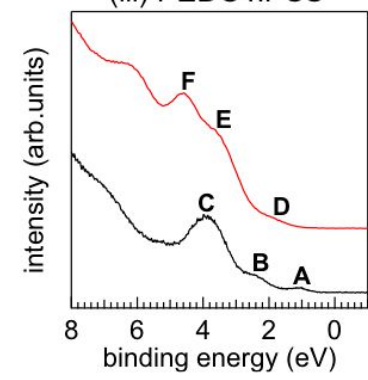

(iv) $\mathrm{UV} / \mathrm{O}_{3}-\mathrm{ITO}$

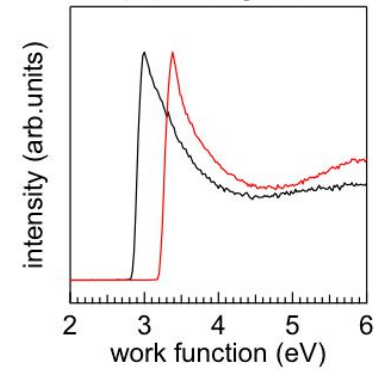

(iv) $\mathrm{UV} / \mathrm{O}_{3}-\mathrm{ITO}$

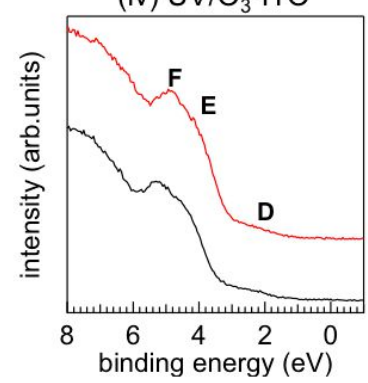

Figure 7. (a) Work function changes for the $\mathbf{1}_{2}$-evaporated electrodes before (black) and after (red) air-exposure for $4 \mathrm{~min}$. (b) Evolution of the valence band spectra of the $\mathbf{1}_{\mathbf{2}}$-covered substrates upon air-exposure [colors correspond to (a)]. Bands A-C and D-F were assigned to the photoelectron emissions from $\mathbf{1}_{\mathbf{2}}$ and $\mathbf{1}^{+}$, respectively. 
(i) air-Ag

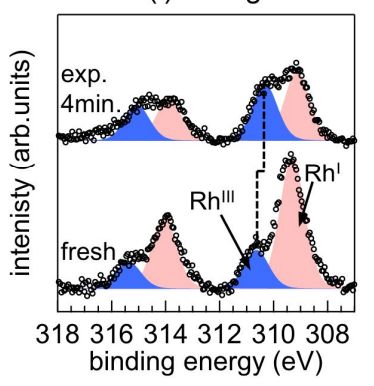

(ii) air-Au

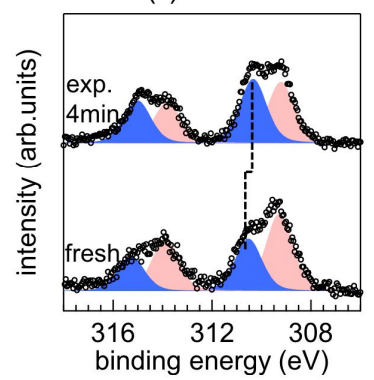

(iii) PEDOT:PSS

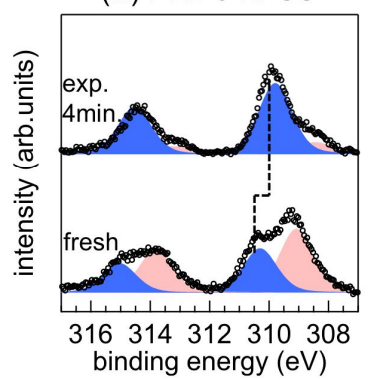

(iv) $\mathrm{UV} / \mathrm{O}_{3}-\mathrm{ITO}$

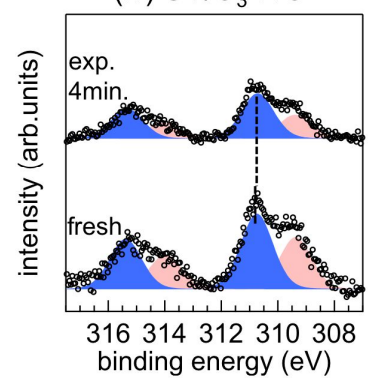

Figure 8. Evolution of the Rh $3 \mathrm{~d}$ core level spectra for the freshly $\mathbf{1}_{2}$-evaporated (bottom) and air-exposed (top) modified electrodes. The dashed lines are guides to visualize the peak shifts.

(a) work function

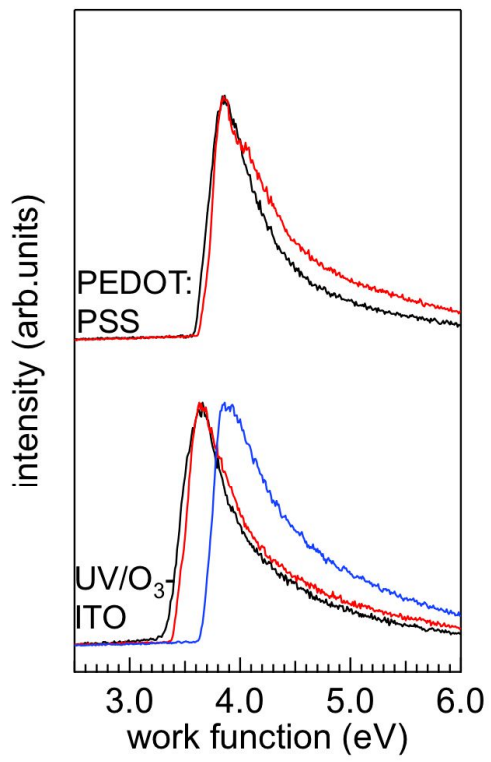

(b) Rh 3d

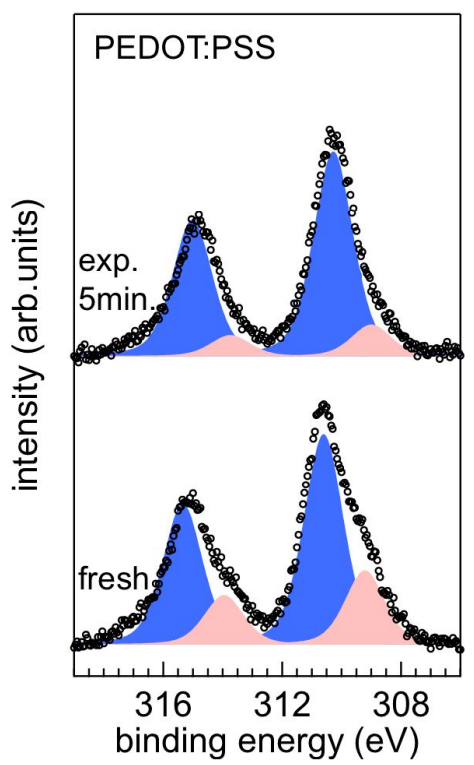

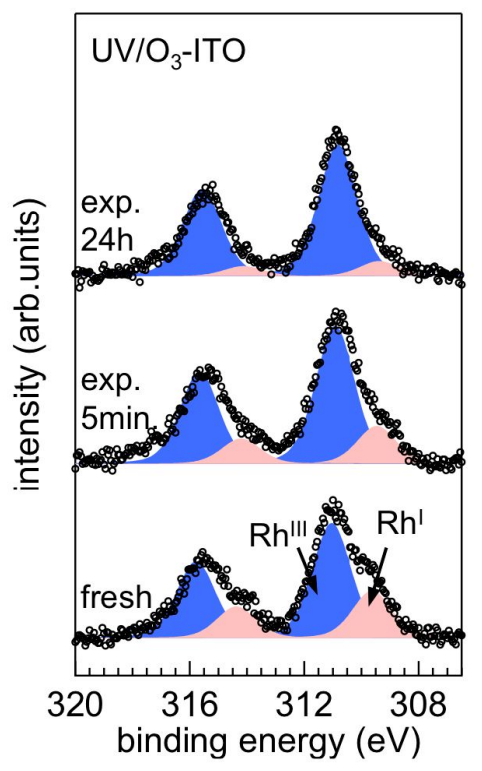

Figure 9. (a) Work function changes for the $\mathbf{1}_{2}$-drop casted $\mathrm{UV} / \mathrm{O}_{3}-\mathrm{ITO}$ and PEDOT:PSS substrates before (black) and after (red) air-exposure for $5 \mathrm{~min}$. The prolonged air-exposure $(24 \mathrm{~h})$ increases the work function of the modified ITO substrate (blue curve at the bottom) by only $0.3 \mathrm{eV}$. (b) Evolution of the Rh $3 \mathrm{~d}$ core level spectra for both substrates upon the airexposure. 


\section{WILEY-VCH}

The air-stable pentamethylrhodocene dimer can render essentially any practical conductive material a low work function electrode, applicable to organic and organic/inorganic hybrid devices, by either evaporation or simple drop-casting. Electron transfer from the dimer to the substrate leads to the appreciable reduction of work function. Technological importance is impaired by the stability of the low work function even after prolonged air-exposure.

Keywords: organometallic dimer, work function reduction, practical electrodes, organic electronic devices, air-stability, photoemission spectroscopy

K. Akaike, M. V. Nardi, M. Oehzelt, J. Frisch, A. Opitz, C. Christodoulou, G. Ligorio, P. Beyer, M. Timpel, I. Pís, F. Bondino, K. Moudgil, S. Barlow, S. R. Marder, N. Koch*

Effective work function reduction of practical electrodes using an organometallic dimer

ToC figure ((Please choose one size: $55 \mathrm{~mm}$ broad $\times 50 \mathrm{~mm}$ high or $110 \mathrm{~mm}$ broad $\times 20 \mathrm{~mm}$ high. Please do not use any other dimensions))

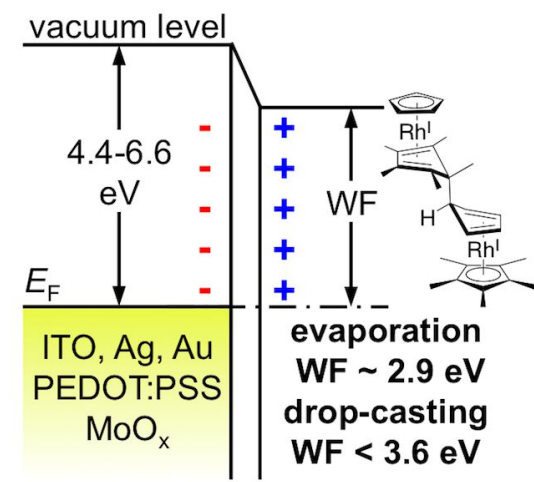




\section{WILEY-VCH}

((Supporting Information can be included here using this template))

Copyright WILEY-VCH Verlag GmbH \& Co. KGaA, 69469 Weinheim, Germany, 2013.

\section{Supporting Information}

Effective work function reduction of practical electrodes using an organometallic dimer

Kouki Akaike, Marco V. Nardi, Martin Oehzelt, Johannes Frisch, Andreas Opitz, Christos Christodoulou, Giovanni Ligorio, Paul Beyer, Melanie Timpel, Igor Pís, Federica Bondino, Kartikkay Moudgil, Stephen Barlow, Seth R. Marder, Norbert Koch*

\section{S1. UPS spectra for $1_{2}$-covered clean $\mathrm{Au}(111)$}
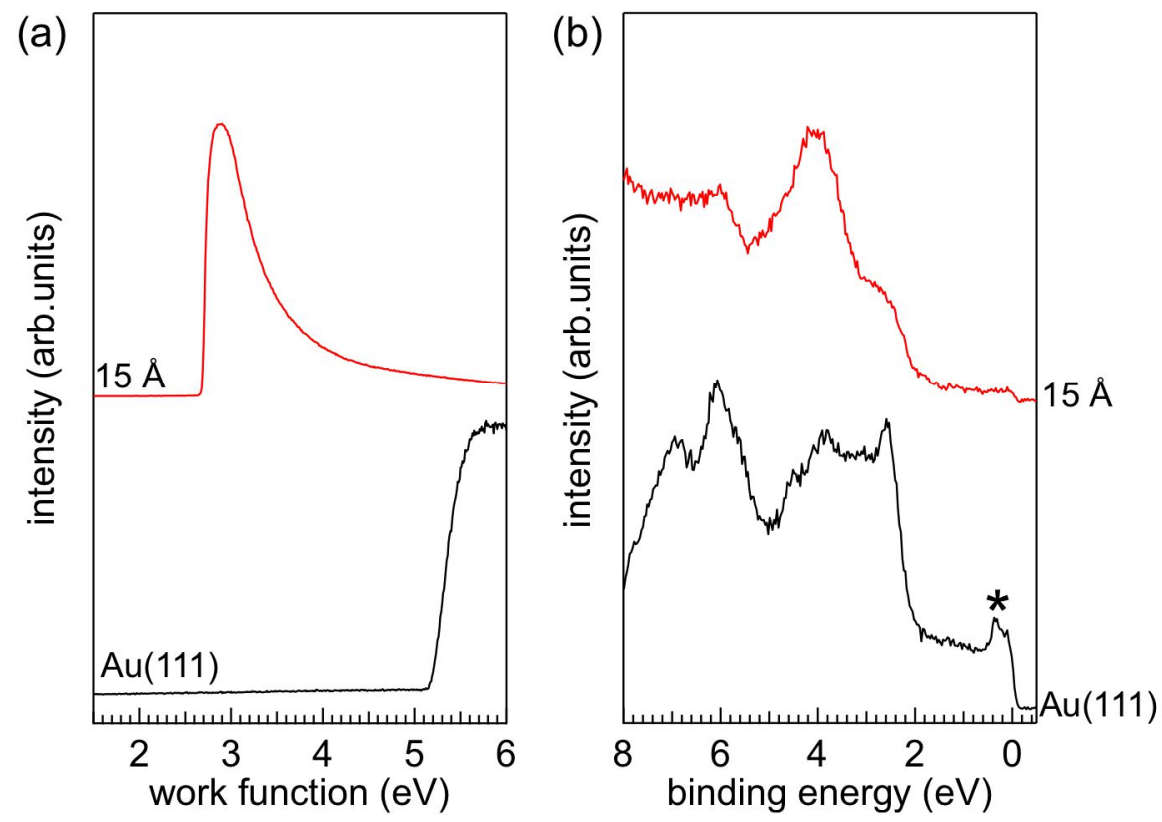

Figure S1. (a) Work function shift of a clean $\mathrm{Au}(111)$ (black) and $15 \AA \mathbf{1}_{\mathbf{2}}$-covered gold substrate (red). (b) Valence band spectra for $\mathrm{Au}(111)$ as well as $\mathbf{1}_{\mathbf{2}}$-covered gold [colors correspond to (a)]. An asterisk shows the surface states of $\mathrm{Au}(111)$. 


\section{WILEY-VCH}

\section{S2. Evolutions of XPS spectra for substrate core levels}
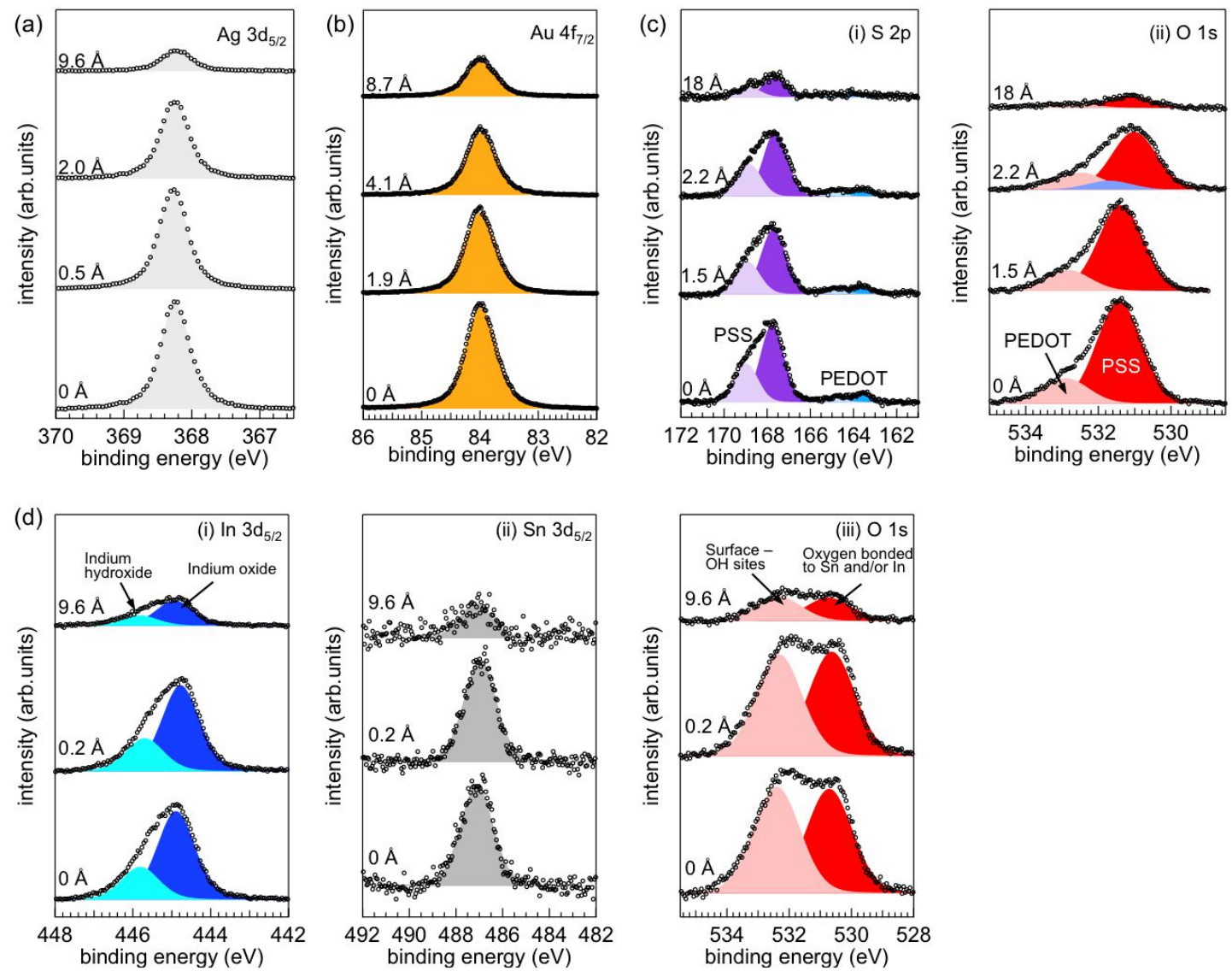

Figure S2. Evolution of substrate core levels with increasing thickness of $\mathbf{1}_{2}$ for (a) air-Ag, (b) air-Au, (c) PEDOT:PSS, and (d) UV/O $\mathrm{O}_{3}$ ITO substrates. The assignments of S $2 \mathrm{p}$ and $\mathrm{O} 1 \mathrm{~s}$ spectra in (c) were carried out referring to ref. [S1]. A new component (blue-colored) is derived from the PEDOT ${ }^{+}$reduced by the adsorption of $\mathbf{1}_{2}$. The assignments of $\mathrm{In} 3 \mathrm{~d}$ and $\mathrm{O} 1 \mathrm{~s}$ spectra in (d) were carried out referring to refs. [S2] and [S3], respectively.

\section{S3. O 1s core level spectra for vacuum-deposited substrates after air-} exposure
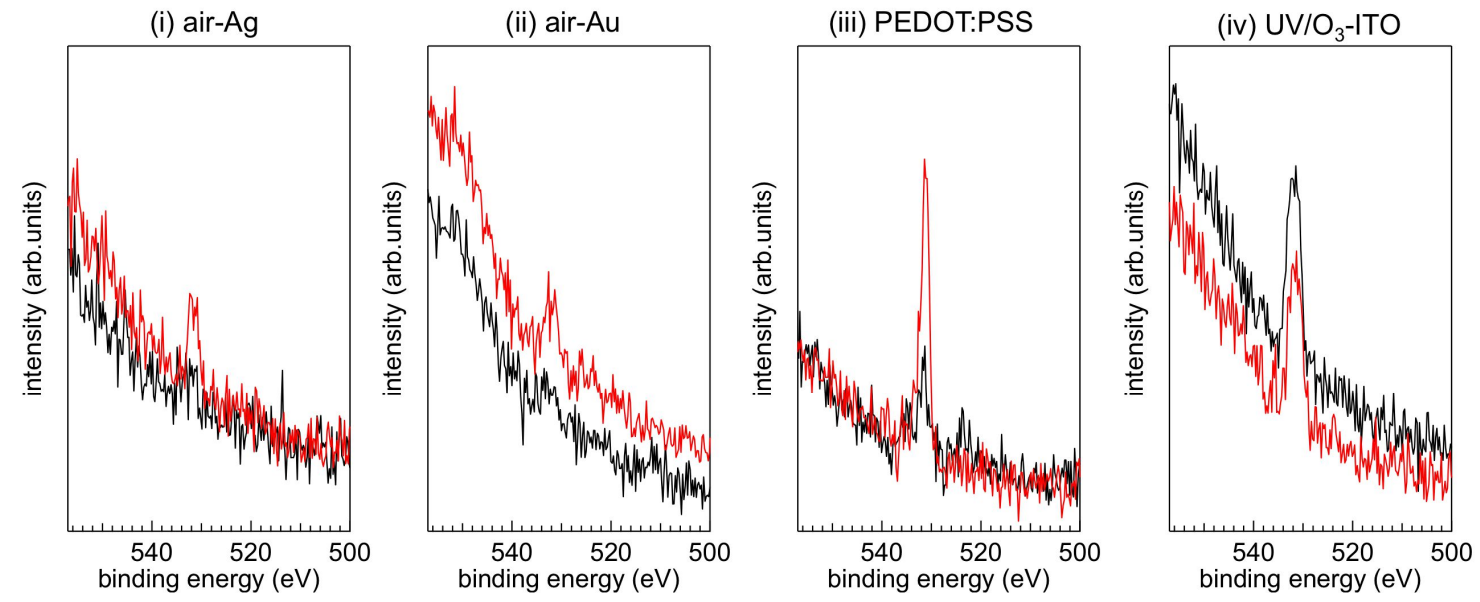

Figure S3. O 1s core level spectra for $\mathbf{1}_{2}$-covered substrates before (black) and after (red) airexposure for $4 \mathrm{~min}$. 


\section{WILEY-VCH}

\section{S4. Substrate core level spectra after air-exposure}
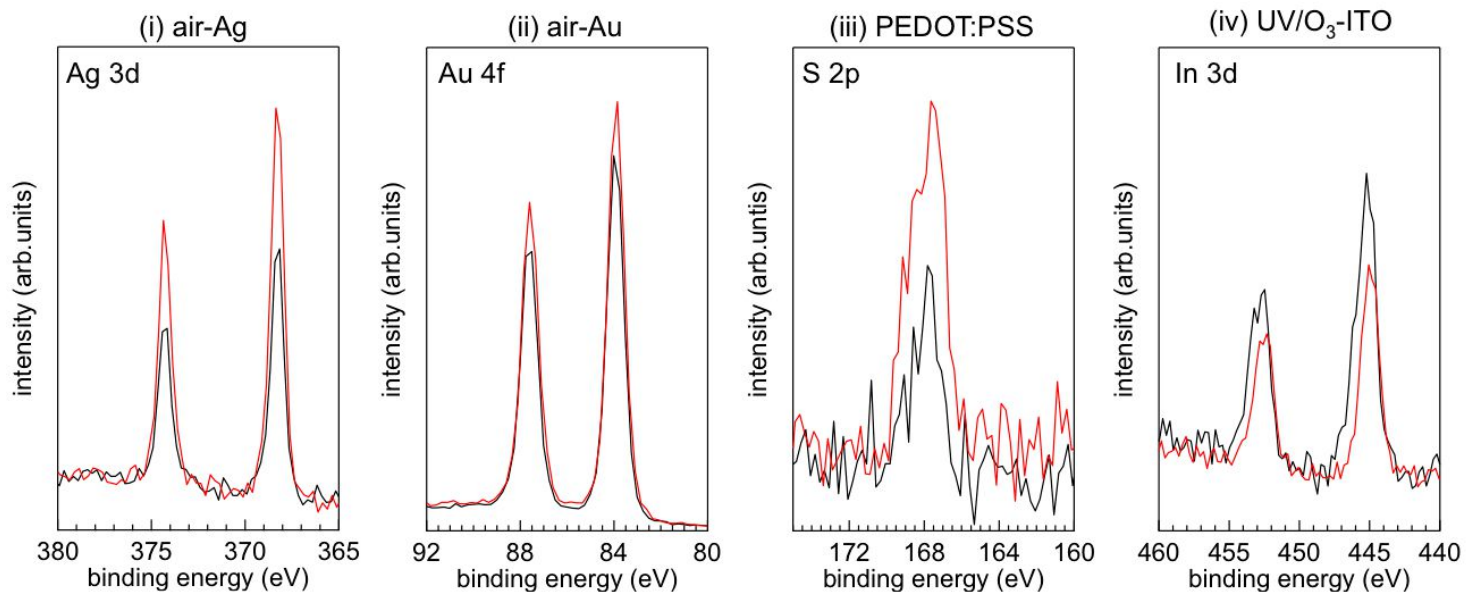

Figure S4. Substrate core levels for $\mathbf{1}_{2}$-covered substrates before (black) and after (red) airexposure for $4 \mathrm{~min}$. Except for the $\mathrm{UV} / \mathrm{O}_{3}-\mathrm{ITO}$, the intensities of core levels for each substrate are enhanced, which suggest that a fraction of the adsorbate desorbs from substrates.

\section{S5. Supporting references}

[S1] G. Greczynski, T. Kugler, M. Keil, W. Osikowicz, M. Fahlman, W. R. Salaneck, J. Electron. Spec. Relat. Phenom. 2001, 121, 1.

[S2] C. Donley, D. Dunphy, D. Paine, C. Carter, K. Nebesny, P. Lee, D. Alloway, N. R. Armstrong, Langmuir 2002, 18, 450.

[S3] D. J. Milliron, I. G. Hill, C. Shen, A. Kahn, J. Schwartz, J. Appl. Phys. 2000, 87, 572. 